\title{
Evaluation of PV and QV based Voltage Stability Analyses in Converter Dominated Power Systems
}

DOI:

10.1109/appeec.2018.8566421

\section{Document Version}

Accepted author manuscript

Link to publication record in Manchester Research Explorer

\section{Citation for published version (APA):}

Sewdien, V. N., Preece, R., Rueda Torres, J. L., \& van der Meijden, M. A. M. M. (2018). Evaluation of PV and QV based Voltage Stability Analyses in Converter Dominated Power Systems. In IEEE APPEEC

https://doi.org/10.1109/appeec.2018.8566421

\section{Published in:}

IEEE APPEEC

\section{Citing this paper}

Please note that where the full-text provided on Manchester Research Explorer is the Author Accepted Manuscript or Proof version this may differ from the final Published version. If citing, it is advised that you check and use the publisher's definitive version.

\section{General rights}

Copyright and moral rights for the publications made accessible in the Research Explorer are retained by the authors and/or other copyright owners and it is a condition of accessing publications that users recognise and abide by the legal requirements associated with these rights.

\section{Takedown policy}

If you believe that this document breaches copyright please refer to the University of Manchester's Takedown Procedures [http://man.ac.uk/04Y6Bo] or contact uml.scholarlycommunications@manchester.ac.uk providing relevant details, so we can investigate your claim.

\section{OPEN ACCESS}




\section{Evaluation of PV and QV based Voltage Stability Analyses in Converter Dominated Power Systems}

\author{
V.N. Sewdien \\ TenneT TSO B.V. \\ Arnhem, The Netherlands \\ Vinay.Sewdien@tennet.eu
}

\author{
R. Preece \\ School of Electrical \& \\ Electronic Engineering \\ University of Manchester \\ Manchester, UK
}

\author{
J.L. Rueda Torres \\ Intelligent Electrical \\ Power Grids \\ Delft University of \\ Technology \\ Delft, The Netherlands
}

\author{
M.A.M.M. van der \\ Meijden \\ Intelligent Electrical \\ Power Grids \\ Delft University of \\ Technology \\ Delft, The Netherlands
}

\begin{abstract}
PV and QV analyses have been widely used in industry. It has already been proven that these steady state methods can be used to assess power system's load ability from voltage stability perspective and that their use in terms of accuracy is justified when compared to time domain simulations. However, this prior validation was carried out for conventional synchronous generator dominated power systems. With increasing levels of power electronics interfaced generation (PEIG) being integrated in power systems, the accuracy of the PV and QV methods for these 'green' power systems can be challenged. This paper investigates to what extend the use of these methods is justified when the power system faces a displacement of conventional generation with PEIG. To this end, assessments with the IEEE 9 bus system and full converter wind turbine generators have been performed in this study. It is shown that, when compared to time domain simulations, the traditional $P V$ and QV analyses do not always accurately predict the saddlenode bifurcation point. Steady state $P V$ analyses show inaccuracies between $1.8 \%$ and $16.8 \%$ (when compared to time domain simulations) in identification of the instability point. The mismatch between steady state and time domain $Q V$ analyses is between $6.1 \%$ and $22.9 \%$. Based on the achieved results, QV analysis is shown to be typically less accurate than PV analysis for PEIG rich systems.
\end{abstract}

Index Terms - MIGRATE, PV Curves, QV Curves, Voltage Stability

\section{INTRODUCTION}

Increasing power electronics interfaced generation (PEIG) is expected to affect the stability of the power system in various ways [1]. In a survey, conducted by CIGRE, among system operators it was found that limited technical studies were performed to assess the fundamentally changing behaviour of the power system [2]. However, where detailed studies were performed, it was concluded that among others voltage stability limits the further integration of PEIG.

In order to assess the small disturbance voltage stability of their networks, industries throughout the world are widely using methods based on PV and QV analyses [3], [4]. Comparisons between steady state methods and equivalent time domain simulations for conventional power systems have already been carried out. From these analyses it was concluded that for conventional synchronous generator dominated power systems, steady state stability analysis approximates time domain simulation results with an acceptable mismatch [5].

With increasing levels of intermittent renewable energy sources (RES), which are mainly connected to the grid using power electronics (PE), the dynamic behaviour of the power system is changing. Therefore it becomes relevant to reassess the suitability and accuracy of these methods used for steady state stability analysis, in light of the increasing PE penetration.

In this paper, steady state PV and QV analyses are carried out and benchmarked against time domain simulations for RES dominated power systems.

\section{LITERATURE REVIEW}

Voltage stability is well defined in [6]. When a power system is operated near its capacity limits, it has an increased likelihood for voltage instability. This is typically analysed using two main approaches: steady state (static) and time domain (dynamic) analysis. Whereas time domain analysis is preferred by most utilities, static analysis is commonly used for online applications where high speed results are required [7]. A comprehensive overview of different line and bus voltage stability indices is given in [8] and [9].

Two widely used static methods are the PV and QV analyses, detailed in [10]. These methods have been used for several analyses in industry as well as academia. In [11] tests are carried out to evaluate the impact of distributed generation (DG) on voltage stability. The voltage stability index in the aforementioned paper is quantified as the power margin to the maximum loading, and is determined in [12] using PV and QV analyses. For the conducted analyses, it was found that voltage stability is not a constraint for distributed generation.

In [13] a study was conducted to evaluate the effectiveness of PV and QV analyses for integration of DG. It was concluded that not only PV, but also QV analyses need to be considered when aiming to select optimum locations for DG. In [14] the applicability of the QV curve as a tool for DG planning was assessed for the Paraguayan power system. The tool, aiming at determining optimal locations for DG, showed promising results.

The focus of the work in [15] was on getting insights in how different control actions impact the operating conditions of the Brazilian power system. To this end, a methodology 
utilizing QV curves was developed and accurate results were achieved. However, with the increasing levels of PEIG in Brazil, it is not clear whether the proposed methodology will remain accurate. Studies performed in [16] show that the outcomes from QV analysis can be pessimistic, resulting in overdesign or overly conservative operation.

Interesting simulations were conducted in [17] on the applicability of line voltage stability indices using dynamic real time simulations. The results from these dynamic simulations could be used to validate steady state analyses of the line voltage stability indices used in the mentioned paper.

Whereas the studies [11]-[15] have utilized PV and QV analyses (be it directly or indirectly), none has assessed its validity in the presence of increasing levels of PEIG. This paper aims to address this gap.

\section{RESEARCH OBJECTIVE \& METHOD}

The objective of this research is to assess whether PV and QV analyses are still accurate with increasing levels of nonsynchronous generation in the power system. The process followed in this paper to investigate this is depicted in Figure 1.

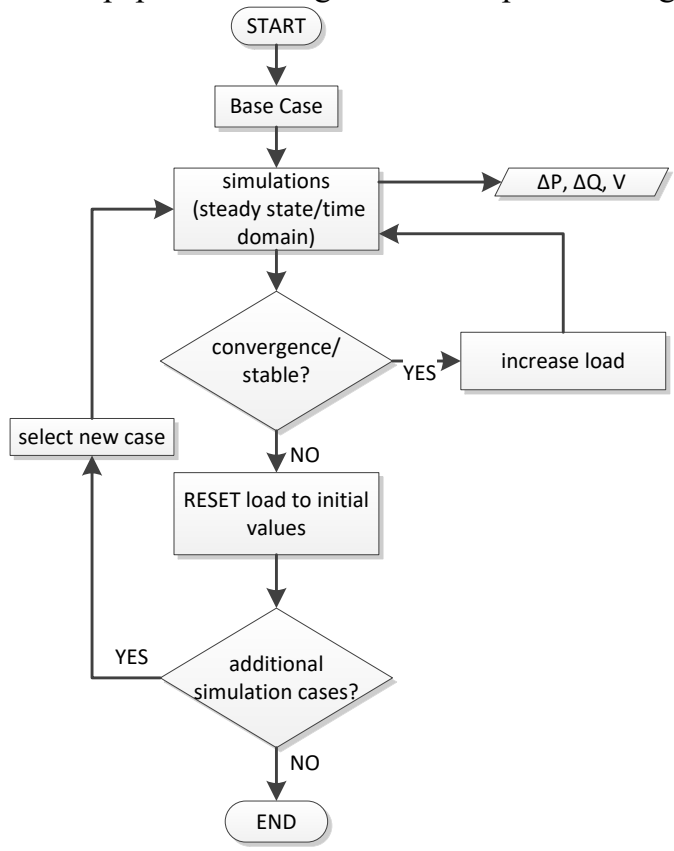

Fig. 1 Simulations Flowchart

For this assessment, the P.M. Anderson 9 bus system (also known as the IEEE 9 bus system) is used [18]. This model contains among others 3 synchronous generators (G1, G2 and G3), 12 buses and 3 constant impedance loads. The individual generator dispatches and loads are given in Table I and Table II. For this study, each of the generators G2 and G3 have been split into 10 parallel machines. The total ratings remained the same. This enables the investigation of the influence of reduced conventional generation (i.e. increased PEIG) on the small disturbance voltage stability.

Furthermore, the system is split into Area A and Area B. Whenever the generation does not match the demand in Area
A, the deficit or surplus of energy is imported from or exported to Area B (Generator G1 is the slack bus).

TABLE I. GENERATOR DISPATCH DATA
\begin{tabular}{|c|c|c|c|}
\hline Generator & Bus & MW & MVAr \\
\hline G1 & 10 & 72 & 28 \\
\hline G2 & 2 & 163 & 5 \\
\hline G3 & 3 & 85 & -11 \\
\hline
\end{tabular}

TABLE II. LOAD DATA
\begin{tabular}{|c|c|c|c|}
\hline Load & Bus & MW & MVAr \\
\hline A & 5 & 125 & 50 \\
\hline B & 6 & 90 & 30 \\
\hline C & 8 & 100 & 35 \\
\hline
\end{tabular}

A set of additional, modified simulation cases, representing increasing PE penetrations, was defined. In these cases one (or multiple) of the parallel machines is completely switched off and replaced with PEIG. For modelling the RES increase, the focus in this paper was on the full converter wind turbine generator (wind turbine generator type 4; schematically given in Figure 2 [19]). The wind turbine generator type 4 (WT T4) model used here was developed in the RMS domain following the IEC Standard 61400-27-1 [20], and is interfaced to the power system using power electronics.

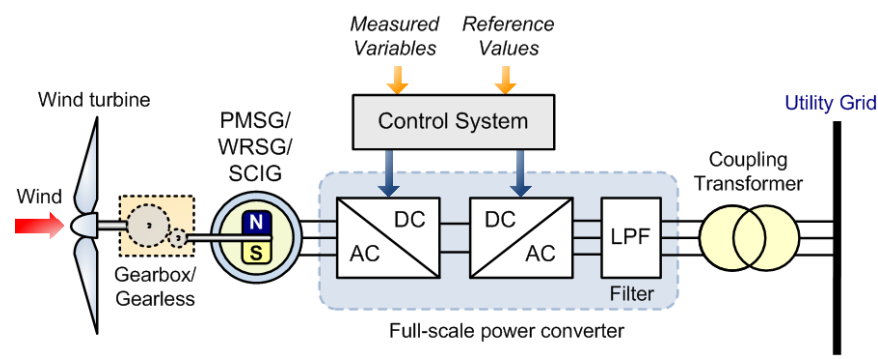

Fig. 2 Wind Turbine Generator Type 4 [19]

To model the increasing levels of RES, WT T4 generators are connected at the same buses as the synchronous generators, representing the replacement of conventional synchronous generation; see Figure 3.

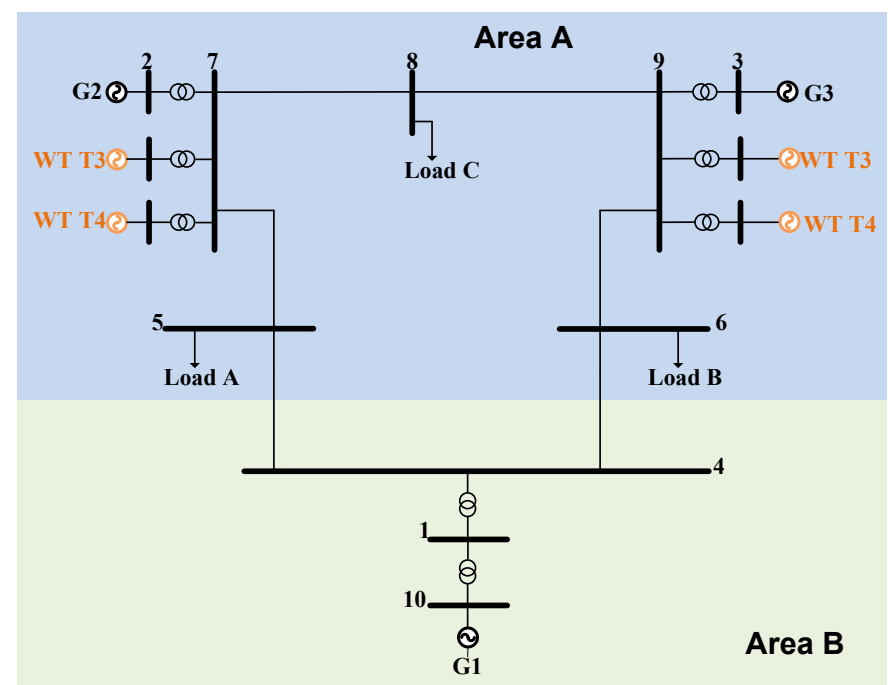

Fig. 3 Modified IEEE 9 Bus System 
For each simulation case static (steady state) and dynamic (time domain) simulations were performed in DIgSILENT PowerFactory, with the aim of identifying the saddle-node bifurcation point of the system. To this end, the system demand was gradually increased in steps of $1 \%$ until non-convergence occurred, after which a new simulation case was selected. The steady state analysis encompasses a series of discrete power flow simulations. Dynamic analysis involves a series of time domain simulations, where after 1 second a small disturbance in the form of a load increase is imposed on the system. The simulation is then run for another 59 seconds. The size of the disturbance is gradually increased with every consecutive simulation.

It should be mentioned that the final results of time domain analysis also depend on the total simulation time of the associated dynamic model. In larger systems, where load tap changing (LTC) transformers are modelled for time domain simulations, the simulation time should be extended, as the transformers settings influence the voltage collapse point. These transformers have initial time delays between 30 to 60 seconds and around 5 seconds mechanism time [16]. Time domain simulations for such large systems could range from minutes to tens of minutes. As no LTC transformers were modelled for the IEEE 9 bus system, this issue is out of scope.

Simulations were performed for PV as well as QV analyses, where active power, reactive power and voltages were recorded. The simulations were automated using Python [21].

\section{RESULTS}

In this section the simulation results are presented for the P.M. Anderson 9 bus system.

\section{A. Dispatch versus Critical Loading}

Figure 4 illustrates the dispatch profiles for generators G2 (bus 7) and G3 (bus 9) and for the wind generation at buses 7 and 9.

The influence of increasing PEIG on the critical loading of the system is also shown. The critical loading here is defined as the saddle-node bifurcation point. The power electronics to load (PE2L) ratio is the ratio of the total PEIG to the system load and is calculated as in Equation (1):

$$
\text { PE2L ratio }=\frac{\sum \text { PEIG }}{\text { System Load }}
$$

With increasing power electronics to load ratios a decreasing trend is observed in the critical loading.

In the graph two regions with a fixed slope for the critical loading can be distinguished: the first region extends up to PE2L ratio 0.6 , while the second region starts at $\mathrm{PE} 2 \mathrm{~L}$ ratio 0.6 . The change in the slope of the curve in the second region is caused by the complete disconnection of generation G2, i.e. there are no more parallel machines of $\mathrm{G} 2$ connected to bus 7 . Up to PE2L ratio 0.6 the number of parallel machines of $\mathrm{G} 2$ was reduced in steps of one.

PE2L ratios larger than 1 imply an export situation (the additional generated energy in this case is absorbed by the slack generator G1 in Area B).

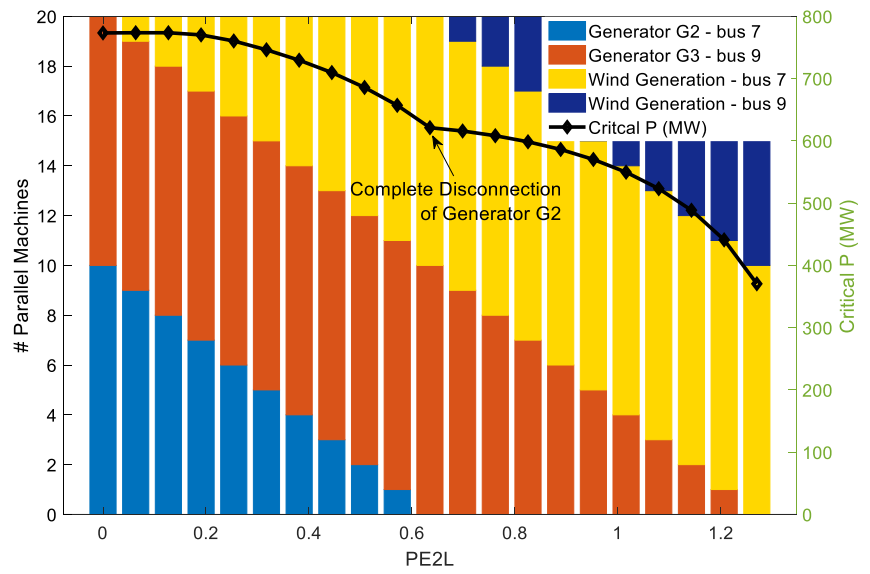

Fig. 4 Generator Dispatches and Critical Loadings for different PE2L ratios

\section{B. $P V \& Q V$ Analyses}

The PV \& QV analyses were conducted for an initial PE2L ratio of 0.7 . For this case all 10 parallel machines of generator G2 (bus 7) and 1 parallel machine of generator G3 (bus 9) were disconnected. The energy deficit resulting from this disconnection was supplied by 10 wind turbines at bus 7 and 1 wind turbine at bus 9. The increase in demand as part of the PV and QV analyses was supplied by re-dispatching generators G1 and $\mathrm{G} 3$ according to their droops.

The simulation results for the PV analysis are shown in Figure 5 (PV curves of bus 4 and 5), Figure 6 (PV curves of bus 6 and 7) and Figure 7 (PV curves of bus 8 and 9).

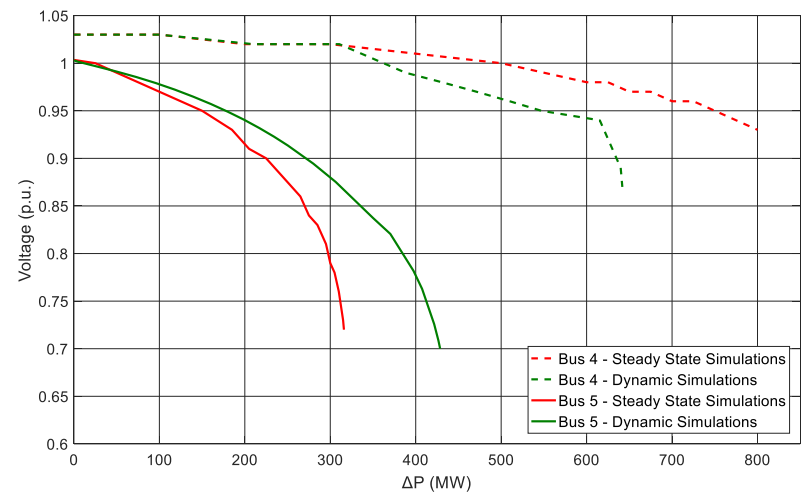

Fig. 5 PV Curves: Bus 4 \& 5

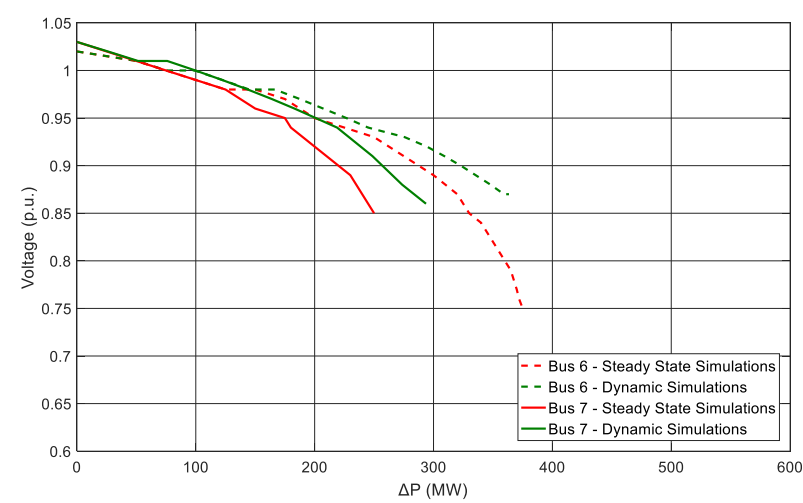

Fig. 6 PV Curves: Bus 6 \& 7 


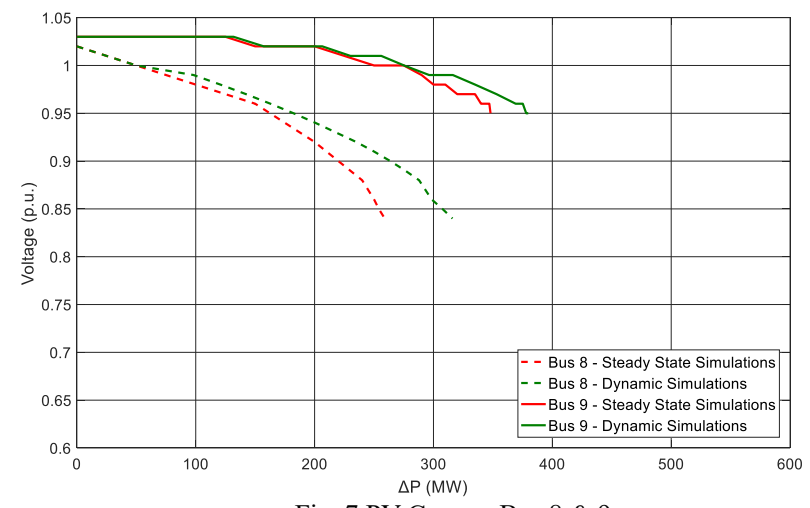

Fig. 7 PV Curves: Bus 8 \& 9

After analysing the results, it was observed that the steady state and dynamic (time domain) simulations do not always have close results. As time domain based stability analysis is more accurate than steady state based stability analysis [5], [16], the former is used as a benchmark for comparing the accuracy/performance of the latter. The discrepancies between the results of the steady state and dynamic PV analysis are shown in Table III.

TABLE III. PV ANALYSIS COMPARISON

\begin{tabular}{|c|c|c|c|c|}
\hline Bus & $\begin{array}{c}\text { Dynamic } \\
\text { (MW) }\end{array}$ & $\begin{array}{c}\text { Steady } \\
\text { State (MW) }\end{array}$ & $\begin{array}{c}|\Delta| \\
(\mathbf{M W})\end{array}$ & $\begin{array}{c}\Delta \\
(\%)\end{array}$ \\
\hline 4 & 955 & 1115 & 160 & 16.8 \\
\hline 5 & 734 & 631 & 103 & 14 \\
\hline 6 & 678 & 690 & 12 & 1.8 \\
\hline 7 & 609 & 582 & 27 & 4.4 \\
\hline 8 & 631 & 674 & 43 & 6.8 \\
\hline 9 & 695 & 663 & 32 & 4.6 \\
\hline
\end{tabular}

It can be observed that the steady state simulations overestimates the critical loading in certain cases (buses 4,6 , and 8; grey shaded in Table III), whereas in other cases it underestimates it (buses 5, 7, and 9). With most accuracies smaller than $7 \%$, the difference between both simulations ranges from $1.8 \%$ (bus 6) to $16.8 \%$ (bus 4 ).

The simulation results for the QV analysis are shown in Figure 8 (QV curves of bus 4 and 5), Figure 9 (QV curves of bus 6 and 7) and Figure 10 (QV curves of bus 8 and 9). The discrepancies between the results of the steady state and dynamic QV analysis are shown in Table IV.

TABLE IV. QV ANALYSIS COMPARISON

\begin{tabular}{|c|c|c|c|c|}
\hline Bus & $\begin{array}{c}\text { Dynamic } \\
\text { (MVAr) }\end{array}$ & $\begin{array}{c}\text { Steady } \\
\text { State (MVAr) }\end{array}$ & $\begin{array}{c}|\Delta| \\
\text { (MVAr) }\end{array}$ & $\begin{array}{c}\Delta \\
(\%)\end{array}$ \\
\hline 4 & 615 & 510 & 105 & 17.1 \\
\hline 5 & 365 & 305 & 60 & 16.4 \\
\hline 6 & 356 & 329 & 27 & 7.6 \\
\hline 7 & 279 & 262 & 17 & 6.1 \\
\hline 8 & 287 & 259 & 28 & 9.8 \\
\hline 9 & 385 & 297 & 88 & 22.9 \\
\hline
\end{tabular}

For the QV analysis, steady state simulations consistently lead to conservative results. The difference between the steady state and time domain simulations ranges from $6.1 \%$ (bus 7 ) to $22.9 \%$ (bus 9). Relying solely on traditional steady state based QV analysis will result in overdesign or overly conservative operation of the power system, which in the end reduces its efficiency.

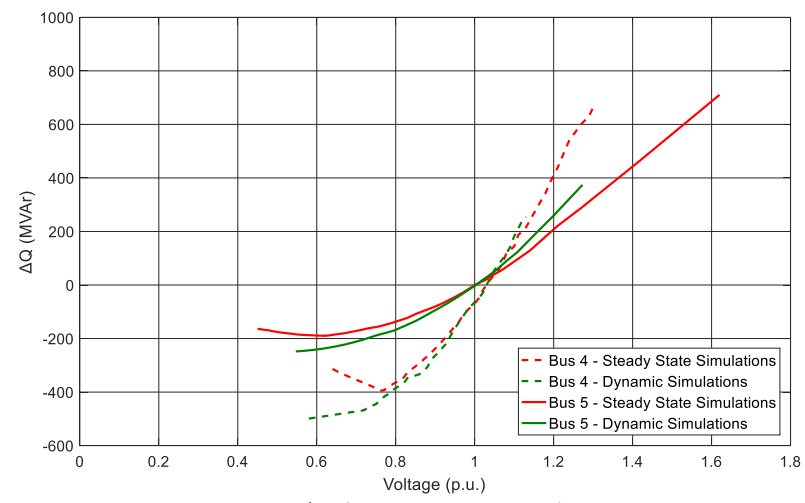

Fig. 8 QV Curves: Bus 4 \& 5

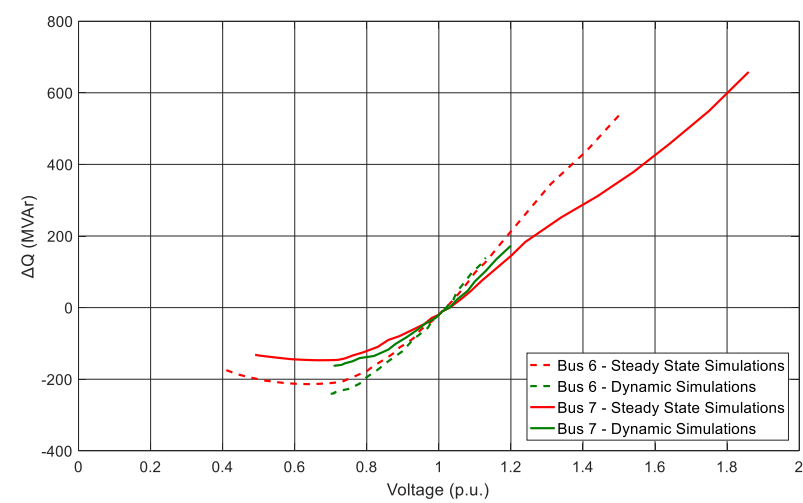

Fig. 9 QV Curves: Bus 6 \& 7

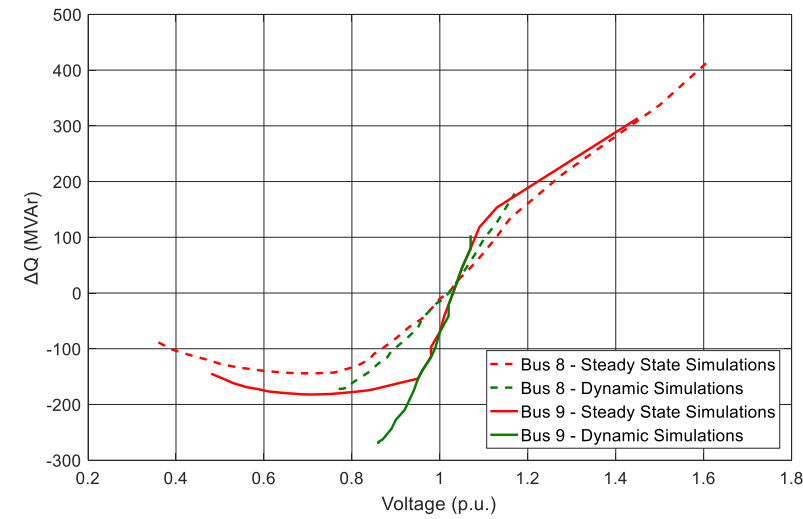

Fig. 10 QV Curves: Bus 8 \& 9

The main conclusions from the results are that steady state and dynamic (time domain) simulations do not always have the same results (i.e. an acceptable mismatch) and that QV analysis tends to be less accurate than PV analysis in PEIG dominated systems. Inaccurate identification of instability points could lead to overinvestments in the system or operating it beyond its security limits. While the first consequence reduces the efficiency of the power system, the second endangers the reliable operation of it.

The assessments performed in this paper were focused on the IEEE 9 bus system. Whereas the obtained results hold true 
for small power systems, it's worth to investigate whether the conclusions remain valid for large power systems.

\section{CONCLUSIONS}

PV and QV analyses are widely used throughout the world to determine the small disturbance voltage stability of power systems. The aim of this research was to investigate if these methods are still suitable for power electronics dominated grids. For this purpose, the IEEE 9 bus system was used, in which increasing levels of full converter wind turbines were integrated. It is shown that the traditional PV and QV curves do not always result in accurate critical points.

PV analysis based on steady state simulations sometimes overestimate and sometimes underestimate the critical loading. For the investigated cases, its accuracy lies between $1.8 \%$ and $16.8 \%$. For QV analysis based on steady state simulations, the results consistently show conservative estimations of the voltage instability point. Its accuracy lies between $6.1 \%$ and $22.9 \%$. Based on the achieved results it is concluded that QV analysis tends to be less accurate than PV analysis in PEIG dominated systems.

Inaccurate identification of instability points could lead to overinvestments in the power system or operating it beyond its security limits. It is therefore concluded that traditional steady state PV and QV analyses should be conducted cautiously in power systems with large amounts of power electronics interfaced generation Future work will focus on similar analyses for large power systems.

\section{ACKNOWLEDGMENT}

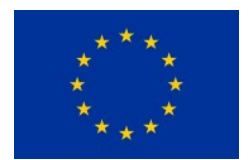

This research was carried out as part of the MIGRATE project. This project has received funding from the European Union's Horizon 2020 research and innovation programme under grant agreement No 691800 . This paper reflects only the authors' views and the European Commission is not responsible for any use that may be made of the information it contains.

\section{REFERENCES}

[1] V. N. Sewdien et al., "Effects of Increasing Power Electronics based Technology on Power System Stability: Performance and Operations," CIGRE Sci. Eng. J., vol. 11, pp. 5-17, June 2018.

[2] CIGRE WG $\mathrm{C} 1 / \mathrm{C} 2 / \mathrm{C} 6.18$, "Coping with limits for very high penetrations of renewable energy," CIGRE, Paris, Technical Brochure 527, 2013.

[3] C. Reis and F. P. M. Barbosa, "A Comparison of Voltage Stability Indices," in Proc. 2006 IEEE MELECON, pp. 1007-1010.

[4] E. Youssef, R. M. El Azab, and A. M. Amin, "Comparative Study of Voltage Stability Analysis for Renewable Energy Grid-Connected Systems Using PSS/E," in Proc. 2015 IEEE SoutheastCon.

[5] G. K. Morison, B. Gao, and P. Kundur, "Voltage stability analysis using static and dynamic approaches," IEEE Trans. Power Syst., vol. 8, no. 3, pp. 1159-1171, 1993.

[6] P. Kundur et al., "Definition and Classification of Power System Stability IEEE/CIGRE Joint Task Force on Stability Terms and Definitions," IEEE Trans. Power Syst., vol. 19, no. 3, pp. 1387-1401, 2004
[7] F. A. Althowibi and M. W. Mustafa, "Power System Voltage Stability: Indications, Allocations and Voltage Collapse Predictions," Int. J. Adv. Res. Electr. , Elecronics Instrumentation Eng., vol. 2, no. 7, pp. 31383152, 2013.

[8] J. Modarresi, E. Gholipour, and A. Khodabakhshian, "A comprehensive review of the voltage stability indices," Renew. Sustain. Energy Rev. vol. 63, pp. 1-12, 2016

[9] F. M. Albatsh, S. Ahmad, S. Mekhilef, H. Mokhlis, and M. A. Hassan, "Optimal placement of unified power flow controllers to improve dynamic voltage stability using power system variable based voltage stability indices," PLoS One, vol. 10, no. 4, pp. 1-32, April 2015.

[10] J. F. Christensen, A. W. Gainger, G. Santagostino, M. Stubbe, and J. Verseille, "Planning against voltage collapse," Electra, Paris, pp. 55-75, 1987.

[11] F. B. Araujo and R. B. Prada, "Distributed generation: Voltage stability analysis," in 2013 IEEE Proc. PowerTech Grenoble, pp. 1-4.

[12] R. B. Prada, E. G. C. Palomino, J. O. R. Dos Santos, A. Bianco, and L. A. S. Pilotto, "Voltage stability assessment for real-time operation," IEE Proc. Gener. Transm. Distrib., vol. 149, no. 2, pp. 175-181, 2002.

[13] G. Nannapaneni, S. Member, T. M. Masaud, and R. Challoo, "A Comprehensive Analysis of Voltage Stability Indices in the Presence of Distributed Generation," in Proc. 2015 IEEE Conf. Technol. Sustain., pp. 96-102.

[14] P. Guimarães, U. Fernandez, T. Ocariz, F. W. Mohn, and A. C. Z. De Souza, "QV and PV curves as a planning tool of analysis," in 2011 4th Int. Conf. Electr. Util. Deregul. Restruct. Power Technol., pp. 16011606.

[15] D. Marujo, A. C. Z. De Souza, B. I. L. Lopes, M. V. Santos, and K. L. Lo, "On control actions effects by using QV curves," IEEE Trans. Power Syst., vol. 30, no. 3, pp. 1298-1305, 2015.

[16] B. H. Chowdhury and C. W. Taylor, "Voltage stability analysis: V-Q power flow simulation versus dynamic simulation," IEEE Trans. Power Syst., vol. 15, no. 4, pp. 1354-1359, 2000.

[17] M. Cupelli, C. Doing Cardet, and A. Monti, "Comparison of Line Voltage Stability Indices using Dynamic Real Time Simulation," in Proc. 2012 IEEE PES Innov. Smart Grid Technol. Eur. (ISGT Europe), pp. 1-8.

[18] P. M. Anderson and A. A. Fouad, Power system control and stability, New Jersey: IEEE Press, 2003.

[19] V. Yaramasu, B. Wu, P. C. Sen, S. Kouro, and M. Narimani, "Highpower wind energy conversion systems: State-of-the-art and emerging technologies," Proc. IEEE, vol. 103, no. 5, pp. 740-788, 2015.

[20] Electrical Simulation Models - Wind Turbines, IEC Std. 61400-27-1, 2015 .

[21] "Python Language Reference, version 3.6.3." Python Software Foundation, Available at https://www.python.org/. 